http://jmscr.igmpublication.org/home/ ISSN (e)-2347-176x ISSN (p) 2455-0450

crossref DOI: https://dx.doi.org/10.18535/jmscr/v8i2.66

Journal Of Medical Science And Clinical Research

\title{
Comparative study of Dyslipidemia in Diabetic patients with Diabetic Nephropathy and Diabetic patients without Nephropathy
}

\author{
Authors \\ Dr Sunil Kumar ${ }^{1}$, Dr Kaushal Kishore ${ }^{2^{*}}$ \\ ${ }^{1}$ Junior Resident, Department of Medicine, Patna Medical College \& Hospital \\ ${ }^{2}$ Professor, Department of Medicine, Patna Medical College \& Hospital \\ *Corresponding Author \\ Dr Kaushal Kishore
}

\begin{abstract}
Dyslipidemia, is considered as an important risk factor for cardiovascular disease which is frequently complicated with diabetic nephropathy. Management of dyslipidemia in diabetic nephropathy is an extremely important factor because patients with diabetic nephropathy are at a high risk for cardiovascular disease-associated death.

Methods: The present study was conducted to explore the lipid abnormalities in diabetic patients with nephropathy in comparison with diabetic patients without nephropathy. This cross sectional study was conducted in the Department of General Medicine, OPD, \& IPD of Patna Medical College \& Hospital. This study included total 60 patients divided in two groups: diabetic patients with nephropathy group and diabetic patients without nephropathy group. Available data between two groups were analysed.

Results: In our study the commonest age group was 51-60 years in both groups. The mean age of patients in nephropathy and without nephropathy group was $51.96 \pm 8.81$ and $51.466 \pm 7.62$ years respectively. We observed no significant difference for age group between two groups. While comparing the mean fasting and postprandial blood glucose level and HbAlc level between two group nephropathy groups showed significantly higher level compared to without nephropathy group. The percentage of subjects with dyslipidemia was significantly higher in nephropathy group in this study.

Conclusion: Dyslipidemia is an important therapeutic target in the management of diabetes. Furthermore, diabetic nephropathy accelerates abnormal lipoprotein metabolism, which causes the progression of DN as well as cardiovascular disease.
\end{abstract}

\section{Introduction}

Diabetes mellitus is related with a noticeably increased risk of premature atherosclerosis, particularly coronary heart disease (CHD) and peripheral arterial disease ${ }^{[1]}$. Although more current analyses have suggested a less marked effect, most authorities consider diabetes to confer at least a twofold excess risk, independently from other conventional risk factors ${ }^{[2] .}$ Even in people without diabetes, fasting blood glucose concentration and glycated hemoglobin (HbA1c) are associated with the risk of vascular disease ${ }^{\text {[2]. }}$ Dyslipidemia has been considered to play crucial roles in the development and progression towards diabetic nephropathy ${ }^{[3]}$ Impaired lipoprotein metabolism, such as increased low density lipoprotein (VLDL-C) and low-density lipoprotein cholesterol (LDL-C) and decreased high-density lipoprotein cholesterol (HDL-C), is observed in patients with diabetes ${ }^{[4]}$. In addition to these 
quantitative changes, quality changes including small dense $\mathrm{LDL}^{[5]}$ and oxidized LDL (ox-LDL) make lipoproteins more proatherogenic in diabetes. This review article describes our current understanding of the role of dyslipidemia in the development of diabetic nephropathy and the impotance of lipid-lowering therapy to prevent the cardiovascular disease and diabetic nephropathy.

The prevalence of diabetes and its consequent secondary disorders has risen to nearly epidemic proportions in recent years. Diabetes is the leading cause of end-stage renal disease (ESRD) and, consequently, the incidence of ESRD is increasing worldwide. The prevalence of diabetes worldwide was approximately $2.8 \%$ in 2000 and is expected to rise to around $4.4 \%$ by 2030 , according to the World Health Organization. ${ }^{[6]}$ The prevalence of chronic kidney disease (CKD) in the India is 17.2\%, Singh et al. 2013, and the most common associated risk factor of CKD are hypertension, anemia, and diabetes. Some other Indian study conduct on government employer also show a prevalence rate of $13-15 \% .^{[7]}$

\section{Methods}

This hospital based clinical study wasto compare Dyslipidemia in Diabetic patient with Diabetic Nephropathy and Diabetic patient without Nephropathy, who were attending in between June 2017 to December 2019, the Medicine IPD of Patna Medical College \& Hospital.

total number of 60 patients aged between 20-60 years. To determine the prevalence of abnormal lipid profile, microalbuminuria and associated micro vascular complications among diabetic patients. The study divided into 2 groups: Group A [Dyslipidemia in Diabetic patient with Diabetic Nephropathy $(n=30)]$, Group B [Dyslipidemia in Diabetic patient without Nephropathy $(n=30)]$.

\section{Clinical Examination}

Microalbuminuria was estimated using the immunoturbidimetric method using random spot urine sample, blood sugar levels by GOD-POD (glucose oxidase peroxidase) end point method, blood urea nitrogen by GLDH (glutamate dehydrogenase) urease method, serum creatinine by Jaffe's method and lipid profile using enzymatic end point method. Routine Urine examination was done in a random spot sample and analyzed for protein, sugar, blood, pus cells and RBC's. More than 5 leucocytes per high power field were considered as pyuria

\section{Inclusion Criteria}

- Total 60 diabetic subjects aged between 20-60 years of either sex with a known history of type $1 \& 2 \mathrm{DM}$ patients chosen [based on the screening recommendation by American diabetes association (ADA)].

- Diabetic Patients suffering from Dyslipidemia.

- Diabetic Patients suffering from CKD with Dyslipidemia.

- Patients giving informed consent for study.

\section{Exclusion Criteria}

- Patients with acute illness,

- Pregnancy with renal failure.

- Malignancy,

- HIV, HBsAg and VDRL Positive patients will be excluded.

\section{Results}

Table 1: Age Distribution

\begin{tabular}{|l|c|c|c|c|}
\hline \multirow{2}{*}{ Age Group } & \multicolumn{2}{|c|}{$\begin{array}{c}\text { Diabetes with nephropathy } \\
(\mathbf{n}=\mathbf{3 0})\end{array}$} & $\begin{array}{c}\text { Diabetes without nephropathy } \\
(\mathbf{n}=\mathbf{3 0})\end{array}$ \\
\cline { 2 - 5 } & Frequency & Percentage & Frequency & Percentage \\
\hline $\mathbf{2 0 - 3 0}$ & 1 & 6.7 & 2 & 3.3 \\
\hline $\mathbf{3 1 - 4 0}$ & 5 & 16.7 & 3 & 10.0 \\
\hline $\mathbf{4 1 - 5 0}$ & 8 & 33.3 & 10 & 40.0 \\
\hline $\mathbf{5 1 - 6 0}$ & 16 & 43.3 & 16 & 46.7 \\
\hline Total & 30 & 100.0 & 30 & 100.0 \\
\hline Mean \& SD & \multicolumn{2}{|c|}{$51.966 \pm 8.81$} & \multicolumn{2}{c|}{$51.466 \pm 7.62$} \\
\hline pValue & \multicolumn{4}{|c|}{$0.823(\mathrm{NS})$} \\
\hline
\end{tabular}


Table 1 shows the age distribution of the study subjects according to their respective group. In the present study we observed 51-60 years to be the commonest age group consisting of $43.3 \%$ patients in DM with nephropathy group and $46.7 \%$ patients in without nephropathy group. the mean age of patients of DM with nephropathy and without nephropathy was $51.966 \pm 8.81$ and $51.466 \pm 7.62$ years respectively. Above analysis for age distribution we found no statistically significant difference between two groups ( $p$ value $=0.823$ ) .

Table 2: Sex Distribution

\begin{tabular}{|l|c|c|c|c|}
\hline \multirow{2}{*}{ Sex } & \multicolumn{2}{|c|}{$\begin{array}{c}\text { Diabetes with } \\
\text { nephropathy }(\mathbf{n = 3 0})\end{array}$} & $\begin{array}{c}\text { Diabetes without } \\
\text { nephropathy }(\mathbf{n = 3 0})\end{array}$ \\
\cline { 2 - 5 } & Frequency & Percentage & Frequency & Percentage \\
\hline Male & 21 & 70.0 & 18 & 60.0 \\
\hline Female & 9 & 30.0 & 12 & 40.0 \\
\hline Total & 30 & 100.0 & 30 & 100.0 \\
\hline Chi-square & $\begin{array}{l}0.6593 \\
\text { p Value- } 0.416(\mathrm{NS})\end{array}$ \\
\hline
\end{tabular}

Age distribution of the study participants according to their respective group is mentioned in Table 2. In the present study we observed male predominance in both the groups. $70 \%$ patients in diabetes with nephropathy and $60 \%$ patients in diabetes without nephropathy group were male.
Male to female ratio in diabetes with nephropathy and without nephropathy was 2.3:1 and 1.5:1 respectively. While analysing we found no statistically significant difference between two groups of sex distribution ( $\mathrm{p}$ value $=0.416$ ).

Table 3: Blood Glucose and HbA1c Level

\begin{tabular}{|l|c|c|c|c|c|}
\hline \multirow{2}{*}{ Variables } & \multicolumn{2}{|c|}{$\begin{array}{c}\text { Diabetes with } \\
\text { nephropathy }(\mathbf{n = 3 0})\end{array}$} & \multicolumn{2}{c|}{$\begin{array}{c}\text { Diabetes without } \\
\text { nephropathy }(\mathbf{n = 3 0})\end{array}$} & \multirow{2}{*}{ p value } \\
\cline { 2 - 5 } & Mean & \pm SD & Mean & \pm SD & \\
\hline FBG & 201.066 & \pm 22.74 & 173.566 & \pm 14.86 & $<0.001$ \\
\hline PPBG & 387.800 & \pm 46.81 & 284.200 & \pm 25.326 & $<0.001$ \\
\hline HbA1c & 9.003 & \pm 0.99 & 8.383 & \pm 0.89 & 0.02 \\
\hline
\end{tabular}

Table 3 shows the comparison of mean fasting and postprandial blood glucose and HbA1c level between diabetic patients with nephropathy and without nephropathy. The mean fasting blood glucose level in diabetes with nephropathy and without nephropathy group was 201.06 \pm 22.74 and $173.56 \pm 14.86 \mathrm{mg} / \mathrm{dl}$ respectively. Mean fasting blood glucose level in patients with nephropathy and without nephropathy group was
$387.800 \pm 46.81$ and $284.200 \pm 25.326 \mathrm{mg} / \mathrm{dl}$ respectively. The mean HbA1c level in patients with nephropathy and without nephropathy group was $9.003 \pm 0.99$ and $8.383 \pm 0.89 \%$ respectively. We observed statistically significant difference between two groups for FBG, PPBG and HbA1c level as the $p$ value we found was $<0.05$ in every parameter.

Table 4: Mean Serum Urea, Creatinine and eGFR Level

\begin{tabular}{|l|c|c|c|c|c|}
\hline \multirow{2}{*}{ Variables } & \multicolumn{2}{|c|}{$\begin{array}{c}\text { Diabetes with } \\
\text { nephropathy }(\mathbf{n = 3 0})\end{array}$} & \multicolumn{2}{c|}{$\begin{array}{c}\text { Diabetes without } \\
\text { nephropathy }(\mathbf{n = 3 0})\end{array}$} & \multicolumn{2}{c|}{$\begin{array}{c}\mathbf{p} \\
\text { value }\end{array}$} \\
\cline { 2 - 5 } & Mean & \pm SD & Mean & \pm SD & \\
\hline Urea (mg/dl) & 54.286 & \pm 9.30 & 49.483 & \pm 15.83 & $<0.001$ \\
\hline Creatinine (mg/dl) & 2.08 & \pm 0.43 & 1.229 & \pm 0.39 & $<0.001$ \\
\hline Microalbumin (mg/l) & 419.00 & 193.22 & 18.30 & \pm 6.10 & $<0.001$ \\
\hline eGFR (ml/min/1.73 m2) & 35.901 & \pm 13.52 & 68.482 & \pm 34.10 & $<0.001$ \\
\hline
\end{tabular}


The comparison of mean urea, creatinine, microalbumin and eGFR level between two groups is mentioned in Table 4. On comparing the two groups, it was observed that among study subjects the mean level of urea, creatinine, microalbumin and eGFR were significantly different between the two groups.

Table 5: Mean Value of Lipid Profile Parameters

\begin{tabular}{|l|c|c|c|c|c|}
\hline \multirow{2}{*}{ Lipid Profile } & \multicolumn{2}{|c|}{$\begin{array}{c}\text { Diabetes with } \\
\text { nephropathy }(\mathbf{n = 3 0})\end{array}$} & \multicolumn{2}{c|}{$\begin{array}{c}\text { Diabetes without } \\
\text { nephropathy }(\mathbf{n = 3 0})\end{array}$} & \multirow{2}{*}{ p value } \\
\cline { 2 - 5 } & Mean & \pm SD & Mean & \pm SD & \\
\hline Total Cholesterol (mg/dl) & 269.733 & \pm 38.87 & 234.1 & \pm 51.51 & $0.003(\mathrm{~S})$ \\
\hline Triglycerides (mg/dl) & 218.766 & \pm 49.65 & 180.690 & \pm 41.99 & $0.004(\mathrm{~S})$ \\
\hline HDL (mg/dl) & 25.916 & \pm 6.93 & 32.446 & \pm 8.19 & $0.001(\mathrm{~S})$ \\
\hline LDL (mg/dl) & 150.533 & \pm 27.53 & 123.230 & \pm 26.10 & $0.001(\mathrm{~S})$ \\
\hline
\end{tabular}

Table 5 shows the comparison of mean lipid profile parameters between two groups. The mean value of total cholesterol, triglyceride, HDL and LDL in diabetic patients with nephropathy group was $269.733 \pm 38.87,218.766 \pm 49.65,25.916 \pm 6.93$ and $150.533 \pm 27.53 \mathrm{mg} / \mathrm{dl}$ respectively. The mean value of total cholesterol, triglyceride, HDL and LDL in diabetic patients without nephropathy group was $234.1 \pm 51.51,180.69 \pm 41.99,32.446$ \pm 8.19 and $123.23 \pm 26.10 \mathrm{mg} / \mathrm{dl}$ respectively. On comparing the two groups, it was observed that for the mean levelof total cholesterol, Tg, HDL and LDL were significantly different between the two groups $(\mathrm{p}=0.003, \mathrm{p}=0.004, \mathrm{p}=0.001$ and $\mathrm{p}=0.001$ respectively).

Table 6: Comparison of the occurrence of Dyslipidemia

\begin{tabular}{|l|c|c|c|c|c|}
\hline \multirow{2}{*}{ Variables } & \multicolumn{2}{|c|}{$\begin{array}{c}\text { Diabetes with nephropathy } \\
(\mathbf{n}=\mathbf{3 0})\end{array}$} & \multicolumn{2}{c|}{$\begin{array}{c}\text { Diabetes without nephropathy } \\
(\mathbf{n}=\mathbf{3 0})\end{array}$} & \multirow{2}{*}{ p value } \\
\cline { 2 - 6 } & Frequency & Percentage & Frequency & Percentage & $0.03(\mathrm{~S})$ \\
\hline Dyslipidemia & 22 & 73.3 & 14 & 46.7 & $0.49(\mathrm{NS})$ \\
\hline $\begin{array}{l}\text { Atherogenic } \\
\text { dyslipidemia }\end{array}$ & 5 & 16.7 & 4 & 13.3 & \multirow{2}{*}{. } \\
\hline
\end{tabular}

Table: 6 shows the comparison of occurrence of dyslipidemia among study participants according to their respective group. $73.3 \%$ of diabetic patients with nephropathy group and $46.7 \%$ of diabetic patients without nephropathy group had dyslipidemia. $16.7 \%$ patients of nephropathy group and $13.3 \%$ patients of without nephropathy group had atherogenic dyslipidemia. The percentage of subjects with dyslipidemia was significantly higher in nephropathy group in this study $(\mathrm{p}$ value $=0.03$ )

\section{Discussion}

Previous studies have reported conclusively that lipid abnormalities in patients with diabetes mellitus is one of the major problems which is associated with increased risk of cardiovascular disease $^{[8]}$. The most common pattern of dyslipidemia in such patients consists of elevation in serum triglyceride (TG) level and low levels of HDL-C. The observation of our study, apart from agreeing with earlier reports that dyslipidemia is prevalent in diabetic patients, also displayed that dyslipidemia is more severe among diabetic patients with DN than diabetic patients without DN. The percentage of subjects with dyslipidemia was significantly higher in nephropathy group in this study. Proteinuria, which is the indication of diabetic nephropathy, causes an elevated LDL-C fraction, whereas in advanced renal dysfunction, a reduction in HDL-C levels is also observed ${ }^{[9]}$. Post hoc analysis of large scale trials such as the Diabetes Control and Complications Trial (DCCT) revealed that albuminuria is correlated with higher levels of TC, TG, and LDL-C ${ }^{[10]}$. The results of our study show that TC, TG, and LDL-C 
levels were significantly higher among the nephropathy patients.

In our study we found that TC, TG, and LDL-C levels were significantly higher among the nephropathy patients. A similar study among related South Indian population has also shown that TC, TG, HDL-C, and LDL-C were significantly different between diabetic and diabetic nephropathy patients ${ }^{[11]}$. A study conducted even in a different ethnic population has observed results similar to the present study ${ }^{[12]}$. The pattern of dyslipidemia observed in our study was similar to a study reported from Saudi Arabia, ${ }^{[13]}$ where the incidence of dyslipidemia was noted to be in the range of 25$60 \%$ among diabetic patients. There was also some similarity with results of Lipid Research Clinic Prevalent studies, where abnormalities in lipids and lipoprotein were approximately $25 \%$ and $50 \%$ for TG and total cholesterol, respectively ${ }^{[14]}$. Studies from Nigeria also reported similar findings, where hypercholesterolemia was present in $43.5 \%$ and hypertriglyceridemia in $34.8 \%$ of patients presented with Type $2 \mathrm{DM}^{[15]}$. Another study showed that dyslipidemia combined with diabetic nephropathy is not limited to $\mathrm{T} 2 \mathrm{DM}$ subjects, but is present among type 1 patients as well ${ }^{[16]}$.

Many epidemiologic studies examine the role of albuminuria and renal function on dyslipidemia in diabetic patients. A study of 200 Japanese patients with T2D investigated the lipoprotein alterations in diabetic nephropathy, and observed that VLDLC level did not differ at different stages of nephropathy. In patients with elevated serum creatinine levels, higher intermediate-density lipoprotein cholesterol and lower HDLC levels were noted. There were no differences in LDL-C levels in patients with diabetes and those without diabetes ${ }^{[17]}$. A large prospective study using the Hong Kong Diabetes Registry showed that increased macroalbuminuria was a risk factor for developing elevated total cholesterol and LDL C levels. A decreased estimated glomerular filtration rate (eGFR), commencing from $110 \mathrm{ml} / \mathrm{min} / 1.73$ m2, could predict reduced HDL-C levels ${ }^{[18]}$. A small Japanese study confirmed the increased ApoB48 and small dense LDL levels in patients with diabetic nephropathy; the increase in ApoB48 level was higher in patients with macroalbuminuria than in patients with microalbuminuria ${ }^{[19]}$. There is also increasing evidence for the association of dyslipidemia and the occurrence and progression of renal disease in both diabetic and nondiabetic patients. There are several mechanisms by which dyslipidemia could lead to diabetic nephropathy.

\section{Conclusion}

The prevalence of dyslipidemia was highly significant among diabetic patients of this population, more so among nephropathy patients. Dyslipidemia in this patient population was associated with gender, age, obesity, central obesity. Dyslipidemia is an important therapeutic target in the management of diabetes. Furthermore, DN elevates abnormal lipoprotein metabolism, which resulted as the progression of DN as well as cardiovascular disease.

\section{References}

1. Durrington PN. Hyperlipidaemia: diagnosis and management. London: Hodder Arnold; 2007.

2. Emerging Risk Factors Collaboration. Sarwar N, Gao P, et al. Diabetes mellitus, fasting blood glucose concentration, and risk of vascular disease: a collaborative meta-analysis of 102 prospective studies. Lancet. 2010;375:2215-2222.

3. Rutledge JC, Ng KF, Aung HH, Wilson DW. Role of triglyceride-rich lipoproteins in diabetic nephropathy. Nat Rev Nephrol. 2010;6(6):361-70.

4. Hirano T. Abnormal lipoprotein metabolism in diabetic nephropathy. Clin Exp Nephrol. 2014;18(2):206-9..

5. Chehade JM, Gladysz M, Mooradian AD. Dyslipidemia in type 2 diabetes: 
prevalence, pathophysiology, and management. Drugs. 2013;73(4):327-39.

6. Wild S, Roglic G, Green A, Sicree R, King H. Global prevalence of diabetes: Estimates for the year 2000 and projections for 2030. Diabetes Care 2004;27:1047-53.

7. Singh AK, Farag YM, Mittal BV, Subramanian KK, Reddy SR, Acharya $\mathrm{VN}$, et al. Epidemiology and risk factors of chronic kidney disease in India Results from the SEEK (Screening and Early Evaluation of Kidney Disease) study. BMC Nephrol 2013;14:114.

8. Haffner S, M, Lehto S, Ronnemaa $\mathrm{T}$, Pyoratak, Laukso M. Mortality from coronary heart disease in subjects with type 2 diabetes and in non diabetic subjects with and without prior myocardial infarction. N Engl J Med 1998;339:22934.

9. Krolewski AS, Warram JH, Christlieb AR. Hypercholesterolemia: a determinant of renal function loss and deaths in IDDM patients with nephropathy. Kidney Int Suppl 1994;45:S125-31.

10. Jenkins AJ, Lyons TJ, Zheng D, Otvos JD, Lackland DT, McGee D, Garvey WT, Klein RL; DCCT/EDIC Research Group. Lipoproteins in the DCCT/EDIC cohort: associations with diabetic nephropathy. Kidney Int 2003;64:817-28.

11. Suchitra MM, Sheshu Kumar M, Bitla AR, Madhusudhana Rao A, Alok S. Atherogenic dyslipidemia in diabetic nephropathy: lipoprotein (a), lipid ratios and atherogenic index. Int J Res Med Sci 2013;1:455-9.

12. Jisieike-Onuigbo NN, Unuigbe EI, Kalu OA, Oguejiofor CO, Onuigbo PC. Prevalence of dyslipidemia among adult diabetic patients with overt diabetic nephropathy in Anambra state south-east Nigeria. Niger J Clin Pract 2011;14:171-5.
13. Jacobs DR Jr. Plasma lipid distributions in selected North American populations: The lipid research clinic program prevalence study. Lipid Research clinics Program Epidemiologic Committee. Circulation 1970;60:427-39.

14. Agaba IE, Anteyi EA, Puepet FH, Omudu PA, Idoko JA. The clinical pattern of diabetic nephropathy in Type II diabetes mellitus in North Central Nigeria. J Med Tropics 2002;4:10.

15. Attman PO, Knight-Gibson C, Tavella M, Samuelsson O, Alaupovic P. The compositional abnormalities of lipoproteins in diabetic renal failure. Nephrol Dial Transplant 1998;13:2833-41.

16. Abdul-Ramman AN, Olufunsho F. Hyperlipidemia among Saudi diabetic patients-pattern and clinical characteristics. Ann Saudi Med 1995;15:240-3.

17. Shoji T, Emoto M, Kawagishi T, Kimoto E, Yamada A, Tabata T, Ishimura E, Inaba M, Okuno Y, Nishizawa Y. Atherogenic lipoprotein changes in diabetic nephropathy. Atherosclerosis 2001. 156(2): 425-433.

18. Yang X, So WY, Ma R, Ko G, Kong A, Lam C, Ho CS, Cockram C, Chow CC, Tong $\mathrm{P}$, et al. Effects of albuminuria and renal dysfunction on development of dyslipidaemia in type 2 diabetes - the Hong Kong Diabetes Registry. Nephrol Dial Transplant 2008. 23(9):2834-2840.

19. Yamamoto T, So WY, Ma R, Ko G, Kong A, Lam C, Ho CS, Cockram C, Chow CC, Tong $\mathrm{P}$, et al. Significant increase of apolipoprotein B48 levels by a standard test meal in type 2 diabetic patients with nephropathy. J Atheroscler Thromb 2008. 15(4):199-205. 